\title{
Bidding Strategy to Support Decision-Making Based on Comprehensive Information in Construction Projects
}

\author{
Ru Liang, ${ }^{1}$ Zhaohan Sheng, ${ }^{1}$ Feng $X u^{1},{ }^{1}$ and Changzhi $W u^{2}$ \\ ${ }^{1}$ School of Management and Engineering, Nanjing University, Nanjing, Jiangsu 210093, China \\ ${ }^{2}$ Australasian Joint Research Centre for Building Information Modelling, School of Built Environment, \\ Curtin University, Bentley, WA 6102, Australia
}

Correspondence should be addressed to Ru Liang; rliang124@163.com

Received 27 May 2016; Accepted 29 June 2016

Academic Editor: Yong Zhou

Copyright (c) $2016 \mathrm{Ru}$ Liang et al. This is an open access article distributed under the Creative Commons Attribution License, which permits unrestricted use, distribution, and reproduction in any medium, provided the original work is properly cited.

\begin{abstract}
This paper develops a unified method to support contractor for bidding selection in construction projects. A cross-functional contractor with 28 candidate units distributed in the three departments (construction units, design units, and suppliers) is used as an example. This problem is first formulated as a $0-1$ quadratic programming problem through optimizing individual performance and collaborative performance of the candidate units based on individual information and collaborative information. Then, a multiobjective evolutionary algorithm is designed to solve this problem and a bidding selection problem for a major bridge project is used to demonstrate our proposed method. The results show that the decision-maker (DM) obtains a better contractor if he pays more attention to collaborative performance.
\end{abstract}

\section{Introduction}

In bidding process of construction projects, contractors have to make several simultaneous and interdependent decisions despite the limited information available [1]. Numerous studies are concerned with bidding strategies in construction projects [2]. The drawback of these kinds of strategies is that it requires specific information about their competitors. Furthermore, many of them are developed for estimating construction costs rather than estimating bid amounts [3, 4]. In practice, bidding decision of construction projects is a complex decision-making process affected by numerous factors, such as site terrain, environmental conditions, construction method, climate conditions, and funding ability [5].

Bidding performance concerns the relationship among different bidders whose bids are submitted in a competition [6]. Currently, internationalization of construction companies has attracted broad attention and significant research interest because of global economic slowdown and construction demand shrinkage [7]. Similarly, predictive information concerns the competitiveness of contractors which is a potentially valuable asset for multiple DMs involved in the construction procurement process $[6,8]$. For instance, it is frequently stated that "the resulting fierce competition for jobs forces construction companies to look for more sophisticated analytical tools to analyze and improve their bidding strategies" [9]. This leads to the conclusion that "[construction] managers need statistical estimation techniques for effectively mining data generated by auctions to predict future behavior and to dynamically improve operational decisions" [10]. One approach of acquiring competitiveness information is to monitor past bidding behavior, but this is subjectively based in the construction setting [6]. Nowadays, innovative approaches to procurement include sequential markets, dynamic bidding models, combinatorial auctions, online auctions, and market places [6]. Existing conceptual frameworks on bidding selection are developed through scattered efforts in more general construction contexts for assessing and comparing performance of construction companies [11]. Frameworks to address bidding performance are rather sparse since most of them are focusing on bidding accuracy, namely, cost estimating accuracy [12]. Moreover, it is paradoxical since lots of research concerning competitiveness in bidding has been published linking the size of the bidder and the size of the contracts, that is, proving that there are usually some affinities between them [13]. 
A bidding process usually requires adoption of multiphase strategies and criteria $[14,15]$. For instance, Bagies and Fortune [15] divide a bidding process into four main categories: bidding strategies, bidding markup determinations, factors affecting bidding decisions, and bidding decisionmaking process. Meanwhile, identifying the main factors has been studied on project factors $[5,16]$. In addition, several multicriteria bidding models [17] focus on considering various factors to achieve optimal markup decision for construction projects $[18,19]$. However, they usually use an additive utility approach through ignoring possible interdependence between different bidding criteria [1]. Moreover, many studies focus on estimating a successful bidding by effective methods based on project factors [14, 20, 21]. For instance, Wanous et al. [14] identify 35 factors affecting bidding decision, formulate a linear equation based on a staff survey, and propose an assessment model and neural score to determine whether a bidder is advantageous or not. Most of the existing studies focus on identifying relevant factors and dealing with the correlation among factors and bidding results without real case studies.

Inspired by the abovementioned studies which highlighted key attributes that form the basis of the bidding decision-making, various approaches are developed for the contractor to select bidding in construction projects, such as the integrated multiobjective decision-making process [22], the neural networks [23], AHP [24, 25], data envelopment analysis [26], the multiattribute analysis model [27], analytic network process [28], integer programming [29], multiattribute utility theory [30], and the binary goal programming model [31]. These models have insightful implications for the management side of a construction firm and reveal important information about bidding practices and patterns in different construction markets [32]. These approaches have drawn much attention to the area of contractor selection in construction projects and provided basis and new ideas to group decision-making [32]. In addition, group decisionmaking models are applied in outsourcing contracts selection [33], selecting project team members and suppliers [34], and selecting repair contracts [35] in the area of construction projects. Then, some scholars [36, 37] address the contributions of experts from different professions to group decisionmaking for selecting contractors of bidding in construction projects. For instance, Liu et al. [32] establish a two-stage partial least square path modeling aggregation approach to expand the research area of group decision-making in large scale construction projects, with different direction correlations taken into consideration among the evaluation indicators.

Existing research shows that the probabilistic risk analysis is superior to most risk analysis methods. However, this may not be true since probabilistic risk analysis requires adequate and precise data from similar projects implemented in quite similar environments and working conditions to get probability density functions. In practice, collecting such information seems almost impossible because of the uniqueness of each construction project and unique features of every certain contract. Thus, estimations of these experts may be the most useful and dependable information in the cases.
In this paper, we will study contractor selection of bidding in construction projects based on individual information and collaborative information. A 0-1 quadratic programming model of the cross-functional contractors on bidding in construction projects based on individual information and collaborative information is established. The results show that DMs obtain the optimal contractor if they pay more attention to collaborative performance. The major contribution of our method is twofold: (1) The model takes into account different numbers of design units, construction units, and suppliers. We not only optimize individual performance of design units, construction units, and suppliers, but also optimize their collaborative performance. Moreover, our model can be embedded into decision support system of construction projects to deal with large scale and complex contractor selection of bidding based on individual information and collaborative information. (2) A novel multiobjective evolutionary algorithm for solving the 0 -1 quadratic programming model of the cross-functional contractor is presented. In this method, a new strategy is presented to handle congestion among the individuals with simple computation. Based on this algorithm, we can obtain a set of Pareto optimal solutions. Then, DMs can select design units, construction units, and the suppliers according to individual performance and collaborative performance to form a cross-functional contractor. The rest of this paper is organized as follows. Section 2 states contractor selection problem of bidding in construction projects based on individual information and collaborative information. Then, a general description framework of the problem is given. Section 3 formulates this problem as a 0-1 multiobjective optimization problem, and an algorithm is presented to solve the problem in Section 4. Section 5 illustrates the proposed method through a detailed example and Section 6 concludes the paper.

\section{Problem Description}

In this section, we will describe how a contractor selects bidding in construction projects based on individual information and collaborative information. Construction projects are typically user-driven, which allocate tasks step by step through contractors and absorb units from different departments (organizations) in the network structures. A contractor management system of a construction project can be described as multiagents, including owners, design contractors, construction contractors, contractors, and equipment suppliers. Meanwhile, they are also supply-demand systems of construction projects including contracts, suppliers, information, and responsibility. In the following, construction units, design units, and suppliers are taken as an example to illustrate how to form a cross-functional contractor, namely, contractor selection of bidding in construction projects.

As mentioned above, this paper solves contractor selection of bidding in construction projects to form a cross-functional contractor from different departments. For instance, construction units, design units, and suppliers come from department 1, department 2, and department 3 , respectively. We consider both individual information and collaborative information of the candidate units. 


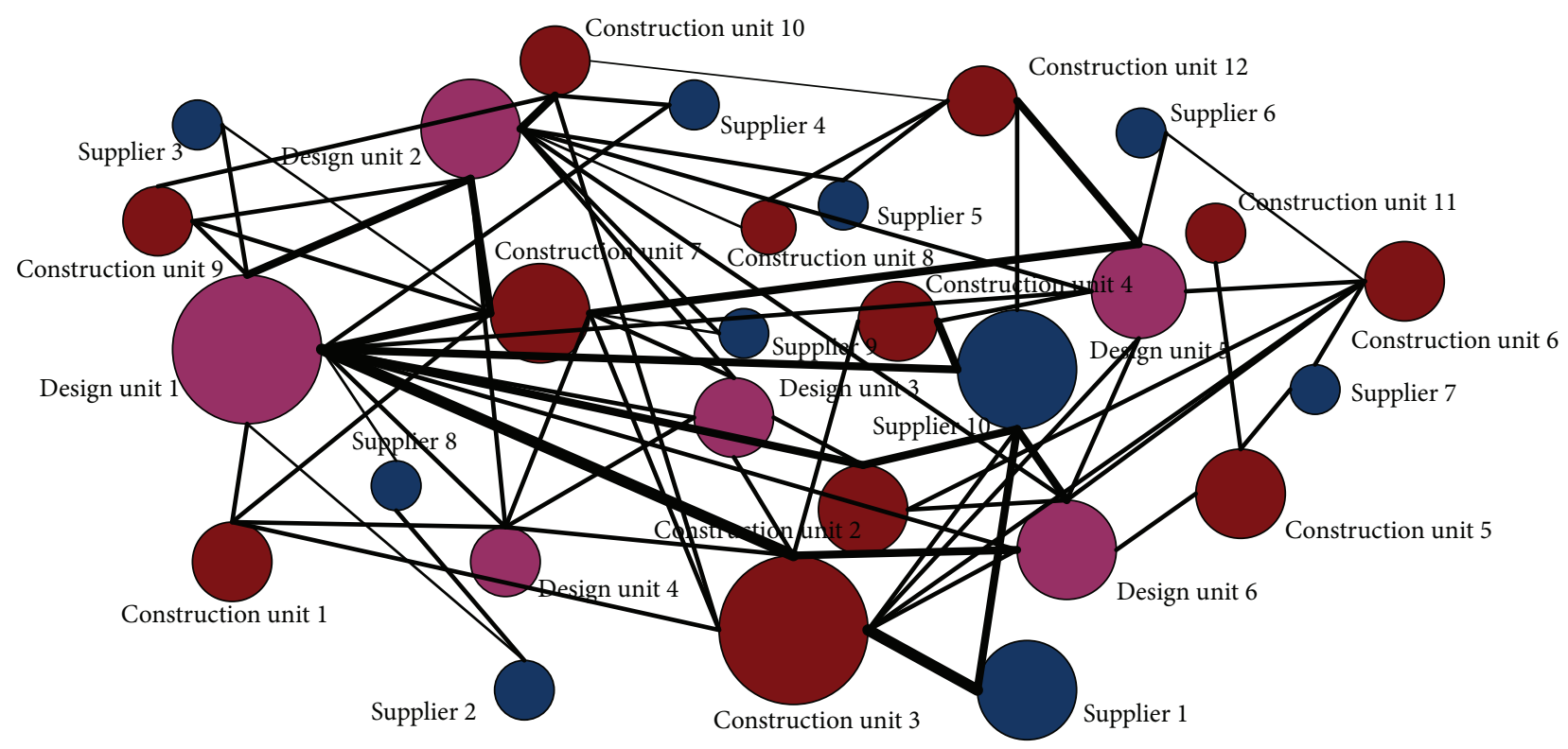

FIgURE 1: Collaborative network constitutes 28 candidate units distributed in 3 departments.

Individual information refers to special characteristics of individual candidate units, such as working experience, qualification rate of completion inspection and acceptance, and professional knowledge. Collaborative information refers to historical relations of cooperation to complete tasks in the past between two candidate units distributed in two different departments. We select a contractor distributed in three departments with 28 candidate units (design units, construction units, and suppliers) shown in Figure 1 as an example, where pink circles denote design units; red circles indicate construction units; blue circles denote suppliers; and solid lines indicate interaction between two different units. Our target is to select one design unit from department 1 , one construction unit from department 2 , and one supplier from department 3, respectively. The distribution of the candidate units can be described through a collaborative network based on interactions among the individual candidate units.

In Figure 1, there are 6 design units, 10 suppliers, and 12 construction units from the 28 candidate units. On the one hand, if circle areas of units are greater, the units have greater individual performance than the other units from the same departments. For instance, because the circle area of design unit 1 from department 1 is obviously larger than the other design units from department 1 , the individual performance of design unit 1 is better than the others in department 1 . Similarly, construction units of department 2 and suppliers of department 3 have the same characteristic as department 1. However, it is worth mentioning that this feature is effective only when the two units come from the same department. For instance, the individual performance of supplier 10 of department 3 cannot compare with the individual performance of construction unit 3 from department 2, even though the circle area of construction unit 3 is larger than the circle area of supplier 10. Different departments usually have different estimated indexes on individual performance. In order to calculate expediently, this paper adopts common estimated indexes of the three departments. On the other hand, horizontal lines indicate the interaction among different units. According to different departments, there are two kinds of the interaction. If two units come from one department, then the interaction between them refers to synergistic effect under estimated indexes of the individual performance. On the contrary, if two units come from two different departments, then the interaction between them refers to synergistic effect under estimated indexes of the collaborative performance. In addition, thicker horizontal lines have larger synergistic effects.

According to the problem described above, contractor selection of bidding in construction projects can be described as in Figure 2. The aforementioned 28 candidate units (12 construction units, 6 design units, and 10 suppliers) distributed in three departments are used to illustrate the problem. Now, we explain four layers of the problem framework as follows:

(1) First Layer. Overall goal of the problem is to form a cross-functional contractor with optimizing individual performance (quality factors, build capacity, delivery cycle, price, etc.) and collaborative performance (cooperation, credibility, etc.).

(2) Second Layer. Under the overall goal, there are two subgoals including optimizing individual performance and collaborative performance.

(3) Third Layer. Individual performance of the candidate units is measured by individual indicators $I_{1}, I_{2}, \ldots, I_{m}$. Meanwhile, collaborative performance of the candidate units is measured by collaborative indicators $C_{1}, C_{2}, \ldots, C_{n}$. 


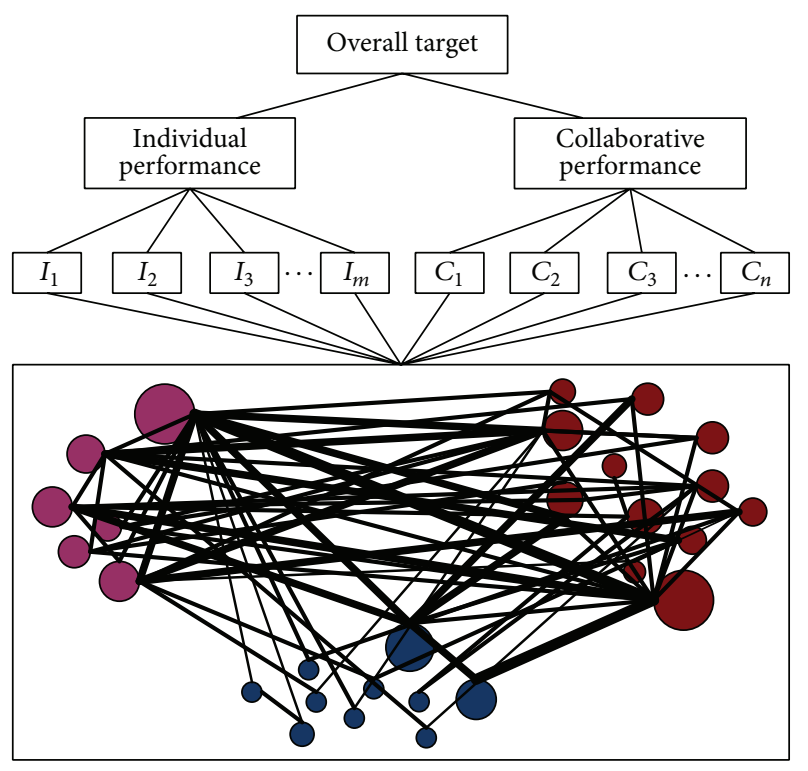

FIGURE 2: A cross-functional contractor selection problem framework.

(4) Fourth Layer. The candidate units which interact with each other are distributed in three different departments in the collaborative network.

\section{Proposed Model}

Based on the problem described in Section 2, this section aims to establish a mathematical model for contractor selection of bidding in construction projects based on individual information and collaborative information. Firstly, we establish a selection model for construction units, design units, and suppliers based on individual information, which is referred to as model 1 . Then, a selection model of construction units, design units, and suppliers based on collaborative information is established, which is referred to as model 2. Secondly, we integrate the two models and obtain an integrated selection model for cross-functional contractors based on individual information and collaborative information. The process for choosing units from the three departments is described in Figure 3.

3.1. Selection Model Based on Individual Information. Let $A=\left[a_{i l}\right]_{n \times l}$ denote individual decision matrix to which $a_{i l}$ is performance on alternative unit $p_{i}$ with regard to individual indicator $I_{l}$. Aiming at contractor selection of bidding in construction projects, individual indicators include work experience, work ability, and professional knowledge. There are two kinds of individual indicators considered in this paper. If individual indicator $I_{l}$ is an objective indicator, corresponding indicator value of $I_{l}$ is statistical data or measured data. If individual indicator $I_{l}$ is a subjective indicator, corresponding indicator value of $I_{l}$ scores from 1 to 10 (1: very poor, 10 : very good) by experts.

A standardized method is effective in measuring indicator values of design units, construction units, and suppliers.
Elements in the matrix $A=\left[a_{i l}\right]_{n \times l}$ can be standardized in the following way:

$$
\begin{aligned}
a_{i l}^{\prime} & =\frac{a_{i l}-a_{l}^{\min }}{a_{l}^{\max }-a_{l}^{\min }}, \quad i=1, \ldots, n ; l=1, \ldots, g, \\
a_{i l}^{\prime} & =\frac{a_{l}^{\max }-a_{i l}}{a_{l}^{\max }-a_{l}^{\min }}, \quad i=1, \ldots, n ; l=1, \ldots, g, \\
a_{l}^{\max } & =\max \left\{a_{i l} \mid i=1, \ldots, n\right\}, \quad l=1, \ldots, g, \\
a_{l}^{\min } & =\min \left\{a_{i l} \mid i=1, \ldots, n\right\}, \quad l=1, \ldots, g .
\end{aligned}
$$

Assume that weight vector of individual indicators is $U=$ $\left(u_{1}, u_{2}, \ldots, u_{g}\right)$, which is obtained by the direct distribution method and the AHP method. Then, we can obtain comprehensive individual performance of design units, construction units, and suppliers through simple linear weighted method as follows:

$$
\alpha_{i}=\sum_{l=1}^{g} u_{l} a_{i l}^{\prime}, \quad i=1, \ldots, n
$$

In the case of only considering individual performance, the performance of candidate unit $p_{i}$ is better if $\alpha_{i}$ is greater. According to comprehensive values $\alpha_{1}, \alpha_{2}, \ldots, \alpha_{n}$ of individual performance, we can obtain the following optimization model:

$$
\begin{array}{ll}
\operatorname{Max} & Z_{1}=\sum_{i=1}^{n} \alpha_{i} x_{i}, \\
\text { s.t. } & \sum_{i \in N_{j}} x_{i}=q_{j}, \quad j=1, \ldots, h, \\
& x_{i} \in\{0,1\}, \quad i=1, \ldots, n,
\end{array}
$$

where $\sum_{j=1}^{h} q_{j}=q$.

Model (6) is a binary optimization problem. It is to select $q$ units from $n$ candidate units (design units, construction units, and suppliers) and to maximize comprehensive values of individual performance. Through descending comprehensive values $\alpha_{1}, \alpha_{2}, \ldots, \alpha_{n}$ of individual performance, we can select headmost $q$ units and obtain the optimal solution directly.

3.2. Selection Model Based on Collaborative Information. Let $D^{m}=\left[d_{i j}^{m}\right]_{n \times n}$ indicate collaborative decision matrix to which $d_{i j}^{m}(i \neq j)$ is performance on alternative unit $p_{i}$ cooperating with alternative unit $p_{j}$ with regard to collaborative indicator $C_{m}$. Aiming at contractor selection of bidding in construction projects, collaborative indicators include cooperative research communication and sharing complementary knowledge base and harmonious culture. In general, imbalanced reciprocities are allowed among collaborative indicators [38]. For example, $p_{i}$ can get benefit from $p_{j}$, but $p_{j}$ will not contribute to $p_{i}$. Thus, for some collaborative indicators, the performance of candidate unit $p_{i}$ coordinated with $p_{j}$ is different from the performance of candidate unit $p_{j}$ coordinated with $p_{i}$, that is, $d_{i j}^{m} \neq d_{j i}^{m}$. 


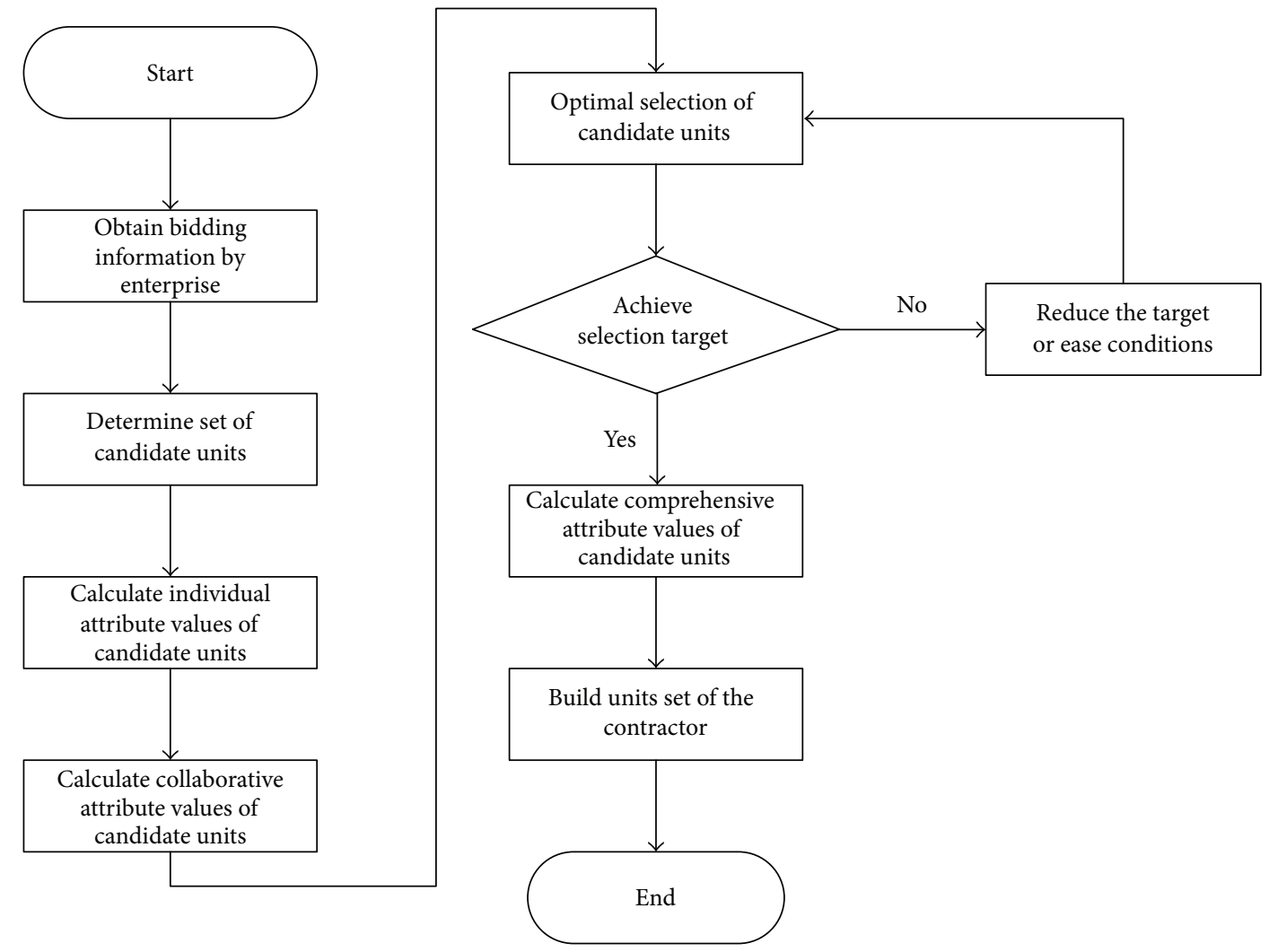

FIGURE 3: Building process for choosing units of the contractor.

Let $d_{i i}^{m}=$ '-' denote that collaborative information of candidate unit $p_{i}$ is not to be considered; namely, diagonal elements of matrix $D^{m}=\left[d_{i j}^{m}\right]_{n \times n}$ are 0 . It should be pointed out that there are three ways of dealing with new candidate units without collaborative information to the existing candidate units of the candidate set. The first way is to consider that collaborative information of new candidate units coordinated with the others is 0 . The second way is to consider that DMs consult cooperation information records of new candidate units in the other departments. The third way is to consider that DMs give their expectations of future cooperation between new candidate units with the others referring to cooperation information records between them.

Similarly, elements in the matrix $D^{m}=\left[d_{i j}^{m}\right]_{n \times n}$ can be standardized, where the calculating formulas are as follows:

$$
d_{i j}^{\prime m}=\frac{d_{i j}^{m}-d^{m \min }}{d^{m \max }-d^{m \min }}
$$

$i, j=1, \ldots, n ; i \neq j ; m=1, \ldots, k$ (efficiency indicators),

$$
\begin{aligned}
d_{i j}^{\prime m} & =\frac{d^{m \max }-d_{i j}^{m}}{d^{m \max }-d^{m \min }}, \\
i, j & =1, \ldots, n ; i \neq j ; m=1, \ldots, k \text { (cost indicators), } \\
d^{m \max } & =\max \left\{d_{i j}^{m} \mid i, j=1, \ldots, n ; i \neq j\right\}, \quad m=1, \ldots, k, \\
d^{m \min } & =\min \left\{d_{i j}^{m} \mid i, j=1, \ldots, n ; i \neq j\right\}, \quad m=1, \ldots, k .
\end{aligned}
$$

Assume that weight vector for collaborative indicators is $V=\left(v_{1}, v_{2}, \ldots, v_{l}\right)$, which could be obtained by direct distribution method and AHP method. Then, we can obtain comprehensive value of collaborative performance between candidate units $p_{i}$ and $p_{j}$ through simple linear weighted method as follows:

$$
\beta_{i j}=\sum_{m=1}^{k} v_{m} d_{i j}^{\prime m}, \quad i, j=1, \ldots, n ; i \neq j .
$$

According to comprehensive values $\alpha_{1}, \alpha_{2}, \ldots, \alpha_{n}$ of collaborative performance, we can obtain the following optimization model:

$$
\begin{array}{ll}
\operatorname{Max} & Z_{2}=\sum_{i=1}^{n} \sum_{j=1, j \neq i}^{n} \beta_{i j} x_{i} x_{j}, \\
\text { s.t. } & \sum_{i \in N_{j}} x_{i}=q_{j}, \quad j=1, \ldots, h, \\
& x_{i} \in\{0,1\}, \quad i=1, \ldots, n,
\end{array}
$$

where $\sum_{j=1}^{h} q_{j}=q$.

In model (12), our target is to select $q$ from $n$ candidate units (design units, construction units, and suppliers) and to maximize comprehensive values of collaborative performance. It is observed that model (12) is a $0-1$ quadratic programming problem. In addition, model (12) is similar to the model established by Kuo et al. [39] for biggest 
differentiation problem, which has been proved as an NPHard problem [39].

3.3. Selection Model of Cross-Functional Contractor. In order to solve contractor selection of bidding in construction projects based on individual and collaborative information, we integrate model (6) and model (12) to the following 0-1 quadratic programming model:

$$
\begin{array}{ll} 
& Z=\lambda \operatorname{Max} Z_{1}+\mu \operatorname{Max} Z_{2} \\
& =\lambda \sum_{i=1}^{n} \alpha_{i} x_{i}+\mu \sum_{i=1}^{n} \sum_{j=1, j \neq i}^{n} \beta_{i j} x_{i} x_{j}, \\
\text { s.t. } \quad & \sum_{i \in N_{j}} x_{i}=q_{j}, \quad j=1, \ldots, h, \\
& x_{i} \in\{0,1\}, \quad i=1, \ldots, n, \\
& 0 \leq \lambda, \mu \leq 1, \\
& \lambda+\mu=1,
\end{array}
$$

where $\sum_{j=1}^{h} q_{j}=q$.

For model (13), its solution space is a function of $n$ and $q$. Let $\Phi$ be number of solutions in the solution space; then the number of possible solutions is

$$
\begin{aligned}
\Phi & =C_{n_{1}}^{q_{1}} \times C_{n_{2}}^{q_{2}} \times \cdots \times C_{n_{h}}^{q_{h}} \leq\left[C_{n / h}^{q / h}\right]^{h} \\
& =\left\{\frac{(n / h) !}{[(n / h)-(q / h)] ! \times(q / h) !}\right\}^{h} .
\end{aligned}
$$

According to properties of combinations, we have $C_{n}^{q}=$ $C_{n}^{n-q}$. When $q \leq n / 2, n-q \leq n / 2$; and when $q / h \ll n / h, \Phi$ could be handled approximately as

$$
\begin{aligned}
\Phi & =C_{n_{1}}^{q_{1}} \times C_{n_{2}}^{q_{2}} \times \cdots \times C_{n_{h}}^{q_{h}} \leq\left[C_{n / h}^{q / h}\right]^{h} \\
& =\left\{\frac{(n / h) !}{[(n / h)-(q / h)] ! \times(q / h) !}\right\}^{h} \\
& \leq\left\{\left(\frac{n}{h}\right) \times\left[\left(\frac{n}{h}\right)-1\right] \times \cdots \times-\left[\left(\frac{n}{h}\right)-\left(\frac{q}{h}\right)+1\right]\right\}^{h} \\
& \leq\left[\left(\frac{n}{h}\right)^{q / h}\right]^{h}=\left(\frac{n}{h}\right)^{q} .
\end{aligned}
$$

Through the above analysis, the number of solutions in the solution space increases exponentially as $q$ increases. Model (12) is NP-Hard, which implied that model (13) is more difficult to solve. Thus, traditional exhaustion methods are only applicable [40] if the problem size is small; namely, $n / h$ and $q$ are small at the same time. If the problem size becomes large, intelligent optimization algorithm is preferred. In this paper, a multiobjective evolutionary algorithm (MOEA) is designed due to larger size of construction units, design units, and suppliers.

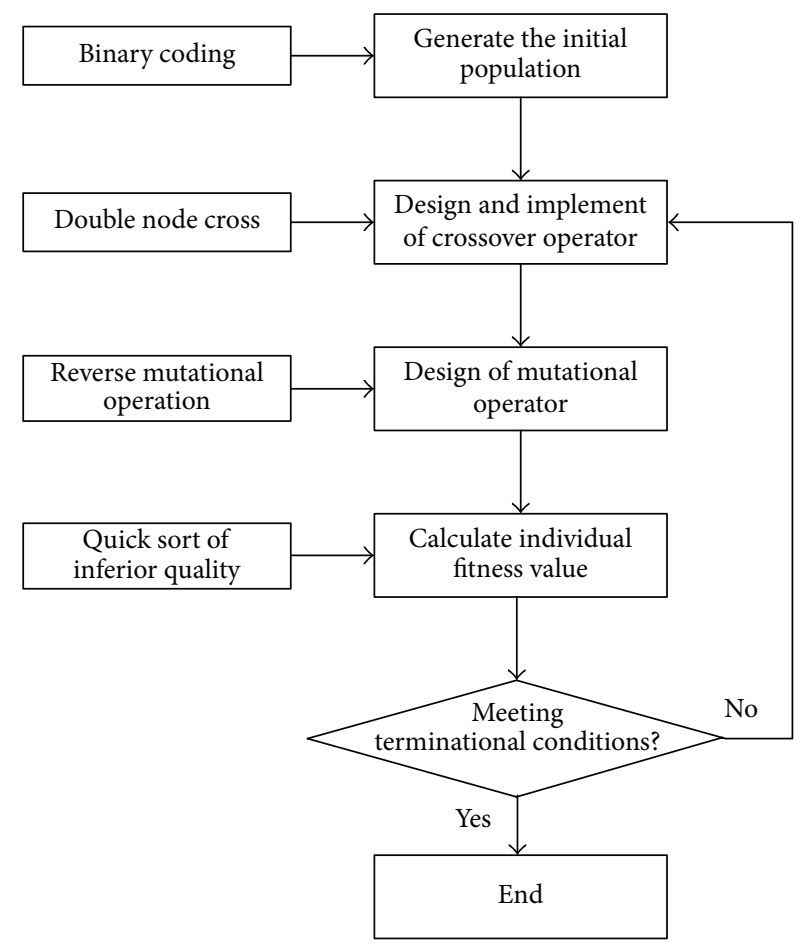

Figure 4: Algorithm process for units selection model of the contractor.

\section{Model Solving}

Evolutionary algorithm for solving multiobjective optimization problems not only can obtain a one-time multiobjective optimization problem of multiple Pareto optimal solutions, but also has good consistency of optimization results. MOEA is such a kind of optimization search method, which mainly includes genetic algorithm, genetic programming, and evolutionary programming $[39,41,42]$. In addition, it has robustness to species of optimization problems. More importantly, its optimized result is also a set for evolutionary operation on population made up of many individuals. Therefore, it is particularly suitable for solving complex NP-Hard problem of multiobjective decision-making (optimization). Therefore, due to characteristics of model (13), we design MOEA of the model. The details of algorithm design process are shown in Figure 4.

4.1. Generate the Initial Population. Using binary coding, namely, $0-1$ code, we encode $[0,1,0, \ldots, 0,1]$ for all construction units, design units, and suppliers of bidding. The total number of encodings (genes) is $n$, where " 1 " denotes construction units, design units, and suppliers that have been selected; " 0 " indicates construction units, design units, and suppliers that have not been selected; blue rectangles denote construction units of department 1 and colorless rectangles indicate candidate units of department 2. For model (13), the number of genes whose values are 1 is $q$. This means that $q$ units are selected. For instance, if $n=6, h=2$, $q_{1}=q_{2}=2, S_{1}=\left\{p_{1}, p_{2}, p_{3}\right\}, S_{2}=\left\{p_{4}, p_{5}, p_{6}, p_{7}\right\}$, then there are seven candidate units for coding. There are 


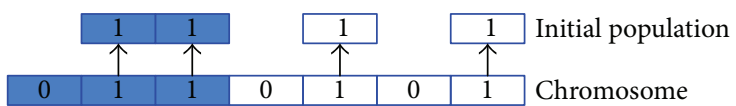

Figure 5: Schematic of encoding rules.

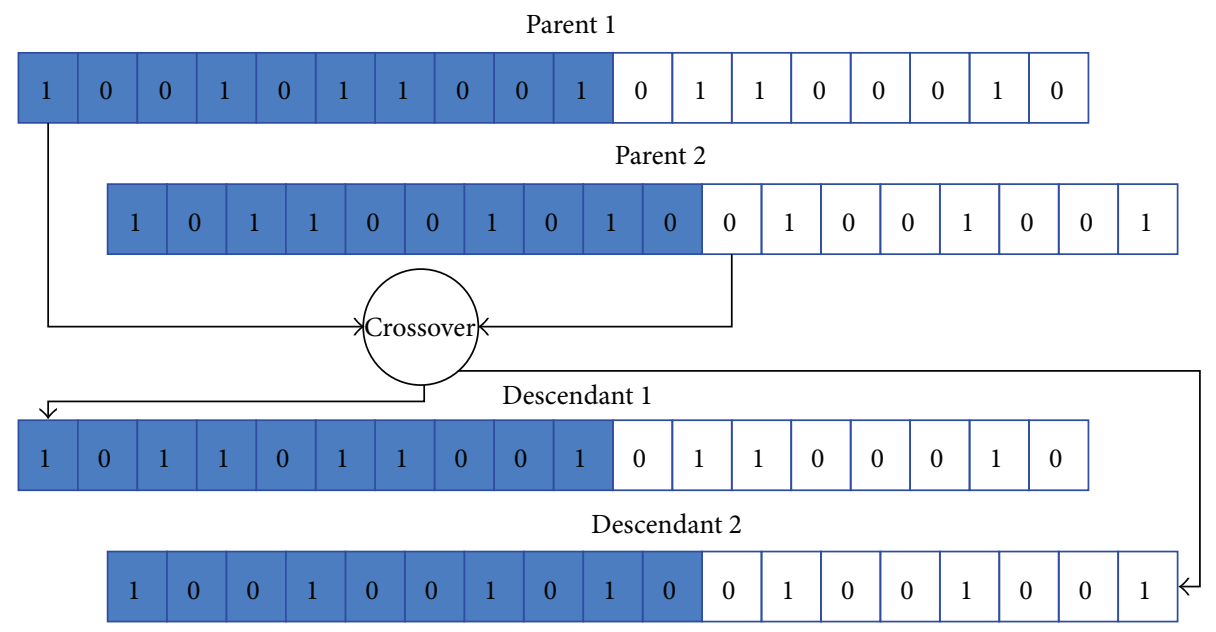

FiguRE 6: Pick-and-replace crossover operators.

four units selected, namely, $p_{2}, p_{3}, p_{5}, p_{7}$. Moreover, $p_{2}$ and $p_{3}$ come from department 1 (e.g., design department). $p_{5}$ and $p_{7}$ come from department 2 (e.g., supplier department). Encoding rules are shown in Figure 5, where candidate units of the design department are $p_{1}, p_{2}, p_{3}$; candidate units of the supplier department are $p_{4}, p_{5}, p_{6}, p_{7}$. All candidate units from left to right are $p_{1}, p_{2}, p_{3}, p_{4}, p_{5}, p_{6}, p_{7}$, which constitute a chromosome (all design units and suppliers of bidding). According to the encoding rules, we define values of $n$ and $q$ in advance. Then we randomly generate the feasible design units and suppliers, and an initial population is constituted finally.

We have to explain that tournament selection strategy is adopted in the algorithm. The specific process is as follows:

(1) $r$ individual units (construction units, design units, and suppliers) are selected randomly in a population (the three departments) each time according to uniform distribution.

(2) Individual units (construction units, design units, and suppliers) with the greatest adaptive values will be selected as individual units to generate descendants.

(3) Parameter $r$ refers to competition scale, and $r=2$ in this paper. Obviously, this option makes individual units with better adaptive values have more opportunities to "survival" (selected). Meanwhile, relative values of the fitness are used to be the choice standard. Thus, it can avoid influence of the super individual units, phenomena of premature convergence, and stagnation to a certain extent.

4.2. Design and Implement of Crossover Operator. In process of biological evolution, two homologous chromosomes restructure by mating, forming a new chromosome and thereby producing new individuals or species. Restructure by mating is a major link in genetic and biological evolution process. Crossover operators are used through imitating this link and producing new individuals (contractors) in evolutionary algorithms. So-called crossover operations in evolutionary algorithms refer to two pairs of chromosomes which are to exchange some of their genes in some manners and to form two new individuals. The new individuals obtain genetic information from two parental individuals and generate more excellent individuals (selected contractor) than parental individuals randomly.

The design and implementation of crossover operators are closely related to our proposed problem. In general, we require it not to damage fine patterns too much with fine properties in a string of coding of the individuals (construction units, design units, and suppliers). Moreover, we also require it to produce some better and new individuals effectively. Thus, crossover operators are designed to unify with individuals coding. Crossover operation adopts double cross nodes. The cross process is as follows:

(1) It randomly generates intersection in two parent individuals.

(2) Then, it exchanges parts between two nodes of parent individuals.

(3) It produces descendants finally.

However, using the above cross method may generate unfeasible solutions. For instance, $n=18, q=8, h=2$, $q_{1}=5, q_{2}=3, S_{1}=\left\{p_{1}, p_{2}, p_{3}, p_{4}, p_{5}, p_{6}, p_{7}, p_{8}, p_{9}, p_{10}\right\}$, $S_{2}=\left\{p_{11}, p_{12}, p_{13}, p_{14}, p_{15}, p_{16}, p_{16}, p_{17}, p_{18}\right\}$, and the process of pick-and-replace crossover operators is shown in Figure 6.

It can be seen that gene fragment 1 of two descendants after crossover operation does not satisfy constraint conditions $q_{1}=5$; namely, the solution is an unfeasible solution. 
Existing research shows that repaired strategies of unfeasible solutions outclass refused strategies and punished strategies for many combinatorial optimization problems. Thus, this paper designs the following repair strategies: we choose one of the descendants, namely, descendant 1 after any cross. At this time, we have statistics number $q_{j}^{*}$ of the descendants that gene values are " 1 ." If $q_{j}^{*}=q_{1}$, it is shown that the descendant is a feasible individual, and there is no need to repair it; if $q_{j}^{*} \neq q_{1}$, statistics number of the descendants has the following two kinds of circumstances to repair:

(1) $q_{j}^{*}>q_{1}$ : randomly generate $q_{j}^{*}-q_{1}$ genes which are selected randomly from the genes with value of " 0 " in the position of genes and the genes with value of " 1 " in fragment 1 of descendant 1 ; then randomly generate $q_{j}^{*}-q_{1}$ genes which are selected randomly from the genes with value of " 1 " in the position of genes and the genes with value of " 0 " in fragment 1 of descendant 2 .

(2) $q_{j}^{*}<q_{1}$ : randomly generate $q_{j}^{*}-q_{j}$ genes which are selected randomly from the genes with value of " 1 " in the position of genes and the genes with value of " 0 " in fragment 1 of descendant 1 ; then randomly generate $q_{j}^{*}-q_{j}$ genes which are selected randomly from the genes with value of " 0 " in the position of genes and the genes with value of " 1 " in fragment 1 of descendant 2 . The reparation ensures that the number of the genes with value 1 in the descendant equals $q_{1}$ and guarantees the individual feasibility to ensure feasibility of the solution.

In the same way, the second section of the genes also conducts similar cross repaired strategies, which can ensure that the number of fragment 2 of descendants such that gene values are " 1 " is $q_{j}(j=1, \ldots, h)$.

4.3. Design of Mutational Operator. In genetic and biological evolution process, the cell division to copy the link may produce some copy error caused by some accidental factors. Then, this can lead to some biological gene mutations somehow and thus can produce new chromosomes that show new biological traits. Although possibility of this kind of variation is small, it is still not negligible to produce new species. To imitate the variation in the process, we introduce the mutational operators to produce new individuals (contractors).

Mutation operation is introduced to reduce local convergence [43]. In addition, individuals use reverse mutation operation in designing algorithms which randomly select two points to reverse variation in gene mutation operation and to reverse the substring between the two points. Clearly, this operation is only to change orders of the individual genes without affecting the values of the genes and thus not to produce infeasible individuals.

4.4. Calculate Individual Fitness Value. Objective function is usually consistent with fitness function in a single objective decision model, but fitness assignment must consider more subobjective functions in the multiobjective decision model.
The specific process of calculating fitness values of individuals in this paper is described as follows: In the target space, according to objective function vectors, individuals are compared in a population and divided into multiple controlled fronts. Obviously, individuals located in the front of the sequence are superior to the others, named Nondominated Sorting. Meanwhile, we introduce the concept of crowded degree. Small crowded degree refers to an individual who has more points in the current population and bigger dense distribution. Then, we can get fit and unfit quality in division according to crowded degrees of all individuals. That is, the greater the crowded degree, the more optimal the individual. The method steps are as follows.

(1) Calculate the Genetic Distances between Individuals. For any two individuals $i$ and $j(j \neq i)$ in solution space, put their chromosomes to be $x_{i}=\left[x_{i 1}, x_{i 2}, \ldots, x_{i n}\right]$ and $x_{j}=$ $\left[x_{j 1}, x_{j 2}, \ldots, x_{j n}\right]$. Then, the genetic distance $D_{i j}$ between them can be obtained by the following formula:

$$
D_{i j}=\sum_{m=1}^{n}\left|x_{i m}-x_{j m}\right| \text {. }
$$

(2) Compare the Genetic Distances among Individuals. Compare genetic distances of one individual with the others; then let the minimum distance $\min \{D i j\}$ be crowded degree of the individual.

Compared with Nondominated Sorting approach, the above method does not need to calculate objective function values of all individuals. Thus, it reduces computational complexity of the algorithm, removes individuals located in densely populated area of the solution space, and keeps diversity of understanding better. According to the argument in the above, values of $q$ determine the solution space. The solution space will increase when $q$ increases. In addition, we could obtain smaller nondominated fronts and shorten calculating and sorting time for distances of crowded degrees. Finally, we could evaluate all the individuals with advantage relations and distances of crowded degrees. Based on the advantages and disadvantages relations, we could give corresponding fitness values.

Based on the above elaboration, we summarize the main steps of the algorithm which are as follows.

Step 1 (generating an initial population). Set up necessary parameters including generations of population evolution maxGen, size of the population popSize, and probability of crossover and mutation $p_{c}, p_{m}$. Generate initial population $P(t), t=0$. Determine adaptive values of all individuals according to fitness assignment method.

Step 2 (selection, crossover, and mutation). Adopt tournament strategy to select firstly. Generate population $P^{*}(t)$ according to given probabilities of crossover and mutation $p_{c}$, $p_{m}$.

Step 3 (combining populations). Combine population $P^{*}(t)$ and population $P(t), t=0$. Generate population $P(t+$ 1) constituted by popSize optimal individuals according to fitness. 
TABLE 1: Indicators system of project bidding.

\begin{tabular}{ll}
\hline Indicators & Description \\
\hline Working experience $\left(I_{1}\right)$ & Work years in this field \\
Qualification rate of completion inspection and acceptance $\left(I_{2}\right)$ & Degree of achieving requirements in the completed projects \\
Professional knowledge $\left(I_{3}\right)$ & The knowledge related to the engineering task in the field \\
History of communication $\left(C_{1}\right)$ & The number of times to communicate and study between units \\
History of cooperation $\left(C_{2}\right)$ & The number of times to help other units for solving problems \\
\hline
\end{tabular}

Step 4 (judging the algorithm). End the algorithm if $t+$ $1>\operatorname{maxGen}$. Put solutions and corresponding vectors of objective function values to be as Pareto optimal solutions (approximate) and Pareto optimal (approximate). Otherwise, return to Step 2.

\section{Calculation Example}

Taking a major bridge project practice in China as problem background, this section illustrates contractor selection of bidding in construction projects using the above proposed model and method.

In order to form a cross-functional contractor, we will select three candidate units from 12 candidate units which are distributed in three different functional-departments. The three departments are design units $S_{1}$, construction units $S_{2}$, and suppliers $S_{3}$, respectively. And the distribution of the candidate units $P_{1}, P_{2}, \ldots, P_{12}$ in the three departments is as follows:

$$
\begin{aligned}
& S_{1}=\left\{P_{1}, P_{2}, P_{3}\right\}, \\
& S_{2}=\left\{P_{4}, P_{5}, P_{6}, P_{7}\right\}, \\
& S_{3}=\left\{P_{8}, P_{9}, P_{10}, P_{11}, P_{12}\right\} .
\end{aligned}
$$

In formed cross-functional contractor, it is required that one unit is selected from each department, namely, $q_{1}=$ $q_{2}=q_{3}=1$. We adopt three individual indicators (working experience, qualification rate of completion inspection and acceptance, and professional knowledge) and two coordinated indicators (history of communication and history of cooperation) to select the unit and description as shown in Table 1 , where $I_{1}$ and $C_{2}$ are objective indicators; $I_{2}, I_{3}$, and $C_{1}$ are subjective indicators. On the one hand, values of indicator $I_{1}$ can be obtained through organization records of human resources departments. And values of indicator $C_{2}$ can be achieved through records of collaborative work systems. On the other hand, values of indicators $I_{2}, I_{3}$, and $C_{1}$ can be scored by experts (1: very poor, 10 : very good). The resulting initial individual information and collaborative information of candidate units are shown in Tables 2-4.
TABLE 2: Initial information of individual indicators $I_{1}, I_{2}$, and $I_{3}$ of candidate units.

\begin{tabular}{lccc}
\hline Candidate units & \multicolumn{3}{c}{ Indicators } \\
\hline$p_{1}$ & $I_{1}$ & $I_{2}$ & $I_{3}$ \\
$p_{2}$ & 21 & 5 & 9 \\
$p_{3}$ & 14 & 1 & 1 \\
$p_{4}$ & 11 & 3 & 8 \\
$p_{5}$ & 30 & 1 & 6 \\
$p_{6}$ & 18 & 1 & 7 \\
$p_{7}$ & 20 & 7 & 7 \\
$p_{8}$ & 25 & 3 & 4 \\
$p_{9}$ & 23 & 4 & 6 \\
$p_{10}$ & 19 & 5 & 5 \\
$p_{11}$ & 28 & 10 & 6 \\
$p_{12}$ & 16 & 4 & 3 \\
\hline
\end{tabular}

Standardize initial information of individual indicators of candidate units using formulas (1), (3), and (4) and standardized initial information as shown in Table 5.

Standardize initial information of collaborative indicators $C_{1}$ and $C_{2}$ of candidate units using formulas (7), (9), and (10) and standardized initial information as shown in Tables 6 and 7.

Assume that weights of individual indicators and collaborative indicators given directly by $\mathrm{DMs}$ are $V=(0.3,0.4,0.3)^{T}$ and $W=(0.6,0.4)^{T}$, respectively. We can obtain comprehensive values of individual information and collaborative information of candidate units using formulas (5) and (11), respectively, as shown in Table 8 . Here elements of main diagonal are comprehensive values of individual performance $\alpha_{i}(i=1, \ldots, n)$, and the other elements are comprehensive values of collaborative performance $\beta_{i j}(i, j=1, \ldots, n ; i \neq$ j).

Based on model (13), we obtain the selection model of design units, construction units, and suppliers in construction contractors as follows:

$$
\begin{aligned}
Z= & \lambda \operatorname{Max} Z_{1}+\mu \operatorname{Max} Z_{2} \\
= & \left(0.64 x_{1}+0.05 x_{2}+\cdots+0.29 x_{11}+0.21 x_{12}\right) \\
& +\left[\left(0.11 x_{1} x_{2}+0.46 x_{1} x_{3}+\cdots+0.25 x_{1} x_{12}\right)+\cdots+\left(0.20 x_{12} x_{1}+0.18 x_{12} x_{2}+\cdots+0.36 x_{12} x_{11}\right)\right],
\end{aligned}
$$




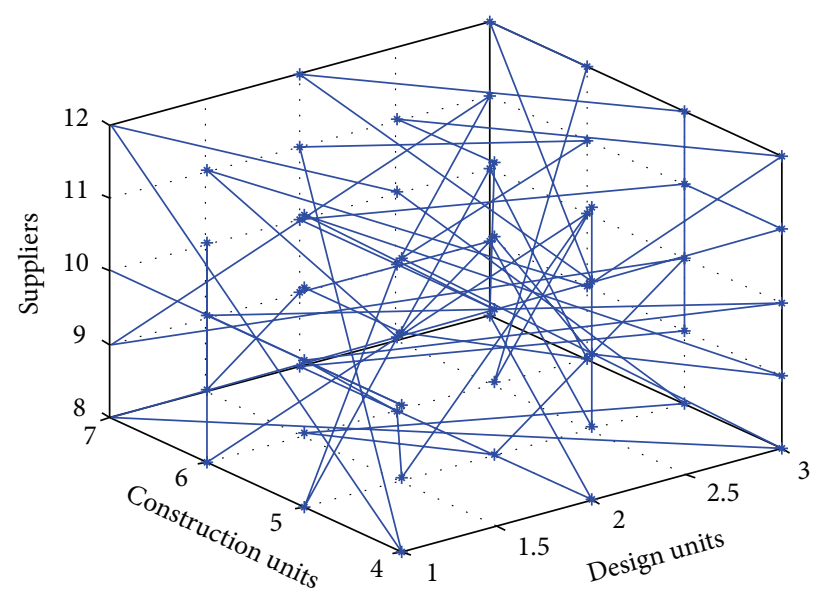

FIGURE 7: Case 1: selection schemes of design units, construction units, and suppliers in construction contractors under the circumstance of individual performance and collaborative performance of the candidate units have the same weight, namely, $\lambda=\mu=0.5$.

$$
\begin{array}{ll}
\text { s.t. } & \sum_{i=1}^{3} x_{i}=1, \\
& \sum_{i=4}^{7} x_{i}=1 \\
& \sum_{i=8}^{12} x_{i}=1, \\
& x_{i} \in\{0,1\}, \quad i=1,2, \ldots, 12 .
\end{array}
$$

Then, there are three different cases discussed. In case 1 , individual performance and collaborative performance of the candidate units have the same weight, namely, $\lambda=\mu=$ 0.5 . We can obtain 60 selection schemes of design units, construction units, and suppliers in construction contractors as shown in Figure 7, according to descending comprehensive performance. In case 2, individual performance has greater weight than collaborative performance. Without loss of generality, we assume $\lambda=0.8, \mu=0.2$. We can obtain 60 selection schemes of design units, construction units, and suppliers in construction contractors as shown in Figure 8, according to descending comprehensive performance. In case 3 , collaborative performance has greater weight than individual performance. Without loss of generality, we assumed $\lambda=$ $0.2, \mu=0.8$. We can obtain 60 selection schemes of design units, construction units, and suppliers in construction contractors as shown in Figure 9, according to descending comprehensive performance. In Figures 7-9, a point stands for a contractor. Moreover, a point includes one design unit, one construction unit, and one supplier denoted by three coordinates, respectively. Obviously, these sets of selection schemes of the three cases are different.

In addition, we compare comprehensive performance of the three cases, as shown in Figure 10. From the overall trend, comprehensive performance of case 3 is the best in the three cases, case 1 takes second place, and case 2 is the worst. For the optimal contractor of the three cases, as shown in Table 9, comprehensive performance of the optimal contractor (design unit 1, construction unit 7, and supplier 11) is $Z_{\text {casel }}=2.345$ in case 1 . Comprehensive performance of the optimal contractor (design unit 1, construction unit 6 , and supplier 10) is $Z_{\text {case2 }}=2.118$ in case 2 . Comprehensive performance of the optimal contractor (design unit 1, construction unit 4 , and supplier 8 ) is $Z_{\text {case3 }}=2.942$ in case 3 . Obviously, comprehensive performance in case 3 is the greatest of all the cases. That is to say, DMs could obtain the optimal contractor if they pay more attention to collaborative performance.

\section{Conclusions}

This paper developed a support decision-making system for contractor selection of bidding in construction projects based on individual indicators and collaborative indicators. Construction units, design units, and suppliers are used to form a cross-functional contractor. Then, a cross-functional contractor with 28 candidate units distributed in the three departments (construction units, design units, and suppliers) is used as an example to explain the method. The best 
TABLE 3: Initial information of collaborative indicator $C_{1}$ of candidate units.

\begin{tabular}{|c|c|c|c|c|c|c|c|c|c|c|c|c|}
\hline & $p_{1}$ & $p_{2}$ & $p_{3}$ & $p_{4}$ & $p_{5}$ & $p_{6}$ & $p_{7}$ & $p_{8}$ & $p_{9}$ & $p_{10}$ & $p_{11}$ & $p_{12}$ \\
\hline$\overline{p_{1}}$ & - & 2 & 6 & 7 & 6 & 3 & 7 & 4 & 8 & 7 & 8 & 3 \\
\hline$p_{2}$ & 2 & - & 6 & 2 & 6 & 7 & 3 & 6 & 1 & 2 & 6 & 3 \\
\hline$p_{3}$ & 6 & 6 & - & 6 & 3 & 3 & 1 & 6 & 2 & 6 & 7 & 2 \\
\hline$p_{4}$ & 7 & 2 & 6 & - & 7 & 1 & 2 & 5 & 6 & 8 & 3 & 6 \\
\hline$p_{5}$ & 6 & 6 & 3 & 7 & - & 5 & 6 & 7 & 2 & 4 & 4 & 4 \\
\hline$p_{6}$ & 3 & 7 & 3 & 1 & 5 & - & 4 & 7 & 4 & 5 & 4 & 3 \\
\hline$p_{7}$ & 7 & 3 & 1 & 2 & 6 & 4 & - & 2 & 1 & 7 & 10 & 5 \\
\hline$p_{8}$ & 4 & 6 & 6 & 5 & 7 & 7 & 2 & - & 8 & 3 & 6 & 2 \\
\hline$p_{9}$ & 8 & 1 & 2 & 6 & 2 & 4 & 1 & 8 & - & 3 & 1 & 6 \\
\hline$p_{10}$ & 7 & 2 & 6 & 8 & 4 & 5 & 7 & 3 & 3 & - & 3 & 7 \\
\hline$p_{11}$ & 8 & 6 & 7 & 3 & 4 & 4 & 10 & 6 & 1 & 3 & - & 5 \\
\hline$p_{12}$ & 3 & 3 & 2 & 6 & 4 & 3 & 5 & 2 & 6 & 7 & 5 & - \\
\hline
\end{tabular}

TABLE 4: Initial information of collaborative indicator $C_{2}$ of candidate units.

\begin{tabular}{|c|c|c|c|c|c|c|c|c|c|c|c|c|}
\hline & $p_{1}$ & $p_{2}$ & $p_{3}$ & $p_{4}$ & $p_{5}$ & $p_{6}$ & $p_{7}$ & $p_{8}$ & $p_{9}$ & $p_{10}$ & $p_{11}$ & $p_{12}$ \\
\hline$p_{1}$ & - & 4 & 13 & 3 & 1 & 7 & 0 & 5 & 4 & 8 & 9 & 12 \\
\hline$p_{2}$ & 25 & - & 5 & 10 & 5 & 3 & 5 & 9 & 3 & 14 & 3 & 14 \\
\hline$p_{3}$ & 1 & 15 & - & 5 & 10 & 4 & 0 & 4 & 19 & 14 & 17 & 6 \\
\hline$p_{4}$ & 1 & 7 & 2 & - & 13 & 25 & 0 & 2 & 13 & 6 & 13 & 7 \\
\hline$p_{5}$ & 2 & 9 & 12 & 3 & - & 6 & 41 & 0 & 12 & 10 & 3 & 11 \\
\hline$p_{6}$ & 13 & 13 & 3 & 11 & 10 & - & 0 & 14 & 6 & 8 & 13 & 0 \\
\hline$p_{7}$ & 3 & 0 & 14 & 8 & 12 & 12 & - & 8 & 7 & 12 & 9 & 14 \\
\hline$p_{8}$ & 5 & 5 & 9 & 0 & 9 & 6 & 0 & - & 15 & 3 & 6 & 14 \\
\hline$p_{9}$ & 0 & 13 & 4 & 4 & 3 & 4 & 9 & 7 & - & 3 & 0 & 9 \\
\hline$p_{10}$ & 0 & 8 & 4 & 6 & 6 & 11 & 7 & 5 & 2 & - & 11 & 0 \\
\hline$p_{11}$ & 14 & 8 & 5 & 10 & 10 & 3 & 6 & 4 & 6 & 3 & - & 13 \\
\hline$p_{12}$ & 7 & 5 & 8 & 11 & 8 & 3 & 3 & 15 & 0 & 8 & 9 & - \\
\hline
\end{tabular}

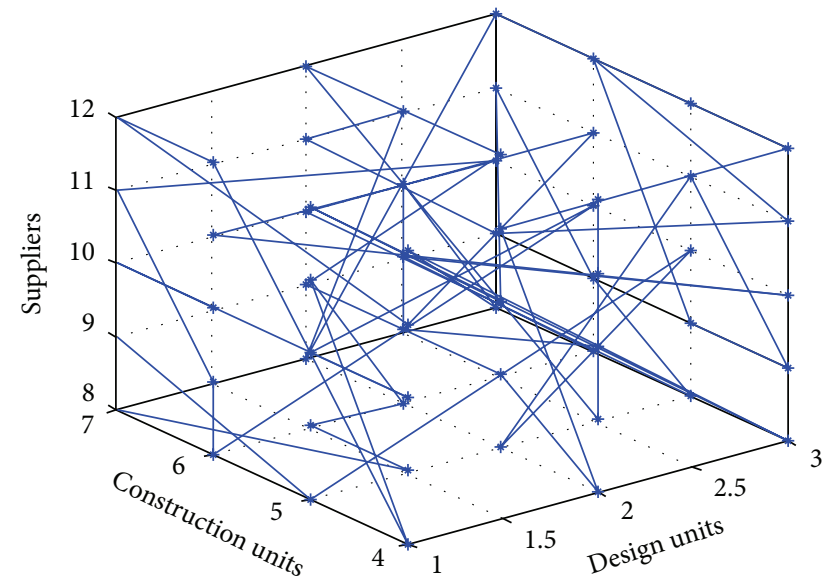

FIgURE 8: Case 2: selection schemes of design units, construction units, and suppliers in construction contractors under the circumstance of individual performance have greater weight than collaborative performance. Without loss of generality, we assumed $\lambda=0.8, \mu=0.2$.

individual performance and collaborative performance are used to formulate the problem as a binary optimization problem. An example including three candidate units from
TABLE 5: Standardized initial information of individual indicators of candidate units.

\begin{tabular}{lccc}
\hline Candidate units & \multicolumn{3}{c}{ Indicators } \\
\hline$p_{1}$ & $I_{1}$ & $I_{2}$ & $I_{3}$ \\
$p_{2}$ & 0.53 & 0.44 & 1.00 \\
$p_{3}$ & 0.16 & 0.00 & 0.00 \\
$p_{4}$ & 0.00 & 0.22 & 0.88 \\
$p_{5}$ & 1.00 & 0.00 & 0.63 \\
$p_{6}$ & 0.37 & 0.00 & 0.75 \\
$p_{7}$ & 0.47 & 0.67 & 0.75 \\
$p_{8}$ & 0.74 & 0.22 & 0.38 \\
$p_{9}$ & 0.63 & 0.33 & 0.63 \\
$p_{10}$ & 0.42 & 0.44 & 0.50 \\
$p_{11}$ & 0.89 & 1.00 & 0.63 \\
$p_{12}$ & 0.26 & 0.33 & 0.25 \\
\hline
\end{tabular}

12 candidate units which are distributed in three different functional-departments (construction units, design units, and suppliers) is used to illustrate our method. As a result of limitation of resources and different preference of DMs, we can further modify the model and increase some objectives 
TABLE 6: Standardized initial information of collaborative indicators $C_{1}$ of candidate units.

\begin{tabular}{ccccccccccccc}
\hline & $p_{1}$ & $p_{2}$ & $p_{3}$ & $p_{4}$ & $p_{5}$ & $p_{6}$ & $p_{7}$ & $p_{8}$ & $p_{9}$ & $p_{10}$ & $p_{11}$ & $p_{12}$ \\
\hline$p_{1}$ & - & 0.11 & 0.56 & 0.67 & 0.56 & 0.22 & 0.67 & 0.33 & 0.78 & 0.67 & 0.78 & 0.22 \\
$p_{2}$ & 0.11 & - & 0.56 & 0.11 & 0.56 & 0.67 & 0.22 & 0.56 & 0.00 & 0.11 & 0.56 & 0.22 \\
$p_{3}$ & 0.56 & 0.56 & - & 0.56 & 0.22 & 0.22 & 0.00 & 0.56 & 0.11 & 0.56 & 0.67 & 0.11 \\
$p_{4}$ & 0.67 & 0.11 & 0.56 & - & 0.67 & 0.00 & 0.11 & 0.45 & 0.56 & 0.78 & 0.22 & 0.56 \\
$p_{5}$ & 0.56 & 0.56 & 0.22 & 0.67 & - & 0.45 & 0.56 & 0.67 & 0.11 & 0.33 & 0.33 & 0.33 \\
$p_{6}$ & 0.22 & 0.67 & 0.22 & 0.00 & 0.45 & - & 0.33 & 0.67 & 0.33 & 0.45 & 0.33 & 0.22 \\
$p_{7}$ & 0.67 & 0.22 & 0.00 & 0.11 & 0.56 & 0.33 & - & 0.11 & 0.00 & 0.67 & 1.00 & 0.45 \\
$p_{8}$ & 0.33 & 0.56 & 0.56 & 0.45 & 0.67 & 0.67 & 0.11 & - & 0.78 & 0.22 & 0.56 & 0.11 \\
$p_{9}$ & 0.78 & 0.00 & 0.11 & 0.56 & 0.11 & 0.33 & 0.00 & 0.78 & - & 0.22 & 0.00 & 0.56 \\
$p_{10}$ & 0.67 & 0.11 & 0.56 & 0.78 & 0.33 & 0.45 & 0.67 & 0.22 & 0.22 & - & 0.22 & 0.67 \\
$p_{11}$ & 0.78 & 0.56 & 0.67 & 0.22 & 0.33 & 0.33 & 1.00 & 0.56 & 0.00 & 0.22 & - & 0.45 \\
$p_{12}$ & 0.22 & 0.22 & 0.11 & 0.56 & 0.33 & 0.22 & 0.45 & 0.11 & 0.56 & 0.67 & 0.45 & - \\
\hline
\end{tabular}

TABLE 7: Standardized initial information of collaborative indicators $C_{2}$ of candidate units.

\begin{tabular}{ccccccccccccc}
\hline & $p_{1}$ & $p_{2}$ & $p_{3}$ & $p_{4}$ & $p_{5}$ & $p_{6}$ & $p_{7}$ & $p_{8}$ & $p_{9}$ & $p_{10}$ & $p_{11}$ & $p_{12}$ \\
\hline$p_{1}$ & - & 0.10 & 0.32 & 0.07 & 0.02 & 0.17 & 0.00 & 0.12 & 0.10 & 0.20 & 0.22 & 0.29 \\
$p_{2}$ & 0.61 & - & 0.12 & 0.24 & 0.12 & 0.07 & 0.12 & 0.22 & 0.07 & 0.34 & 0.07 & 0.34 \\
$p_{3}$ & 0.02 & 0.37 & - & 0.12 & 0.24 & 0.10 & 0.00 & 0.10 & 0.46 & 0.34 & 0.41 & 0.15 \\
$p_{4}$ & 0.02 & 0.17 & 0.05 & - & 0.32 & 0.61 & 0.00 & 0.05 & 0.32 & 0.15 & 0.32 & 0.17 \\
$p_{5}$ & 0.05 & 0.22 & 0.29 & 0.07 & - & 0.15 & 1.00 & 0.00 & 0.29 & 0.24 & 0.07 & 0.27 \\
$p_{6}$ & 0.32 & 0.32 & 0.07 & 0.27 & 0.24 & - & 0.00 & 0.34 & 0.15 & 0.20 & 0.32 & 0.00 \\
$p_{7}$ & 0.07 & 0.00 & 0.34 & 0.20 & 0.29 & 0.29 & - & 0.20 & 0.17 & 0.29 & 0.22 & 0.34 \\
$p_{8}$ & 0.12 & 0.12 & 0.22 & 0.00 & 0.22 & 0.15 & 0.00 & - & 0.37 & 0.07 & 0.15 & 0.34 \\
$p_{9}$ & 0.00 & 0.32 & 0.10 & 0.10 & 0.07 & 0.10 & 0.22 & 0.17 & - & 0.07 & 0.00 & 0.22 \\
$p_{10}$ & 0.00 & 0.20 & 0.10 & 0.15 & 0.15 & 0.27 & 0.17 & 0.12 & 0.05 & - & 0.27 & 0.00 \\
$p_{11}$ & 0.34 & 0.20 & 0.12 & 0.24 & 0.24 & 0.07 & 0.15 & 0.10 & 0.15 & 0.07 & - & 0.32 \\
$p_{12}$ & 0.17 & 0.12 & 0.20 & 0.27 & 0.20 & 0.07 & 0.07 & 0.37 & 0.00 & 0.20 & 0.22 & - \\
\hline
\end{tabular}

TABLE 8: Comprehensive values of individual information and collaborative information of candidate units.

\begin{tabular}{lcccccccccccc}
\hline & $p_{1}$ & $p_{2}$ & $p_{3}$ & $p_{4}$ & $p_{5}$ & $p_{6}$ & $p_{7}$ & $p_{8}$ & $p_{9}$ & $p_{10}$ & $p_{11}$ & $p_{12}$ \\
\hline$p_{1}$ & 0.64 & 0.11 & 0.46 & 0.43 & 0.34 & 0.20 & 0.40 & 0.25 & 0.51 & 0.48 & 0.56 & 0.25 \\
$p_{2}$ & 0.31 & 0.05 & 0.38 & 0.16 & 0.38 & 0.43 & 0.18 & 0.42 & 0.03 & 0.20 & 0.36 & 0.27 \\
$p_{3}$ & 0.34 & 0.48 & 0.35 & 0.38 & 0.23 & 0.17 & 0.00 & 0.38 & 0.25 & 0.47 & 0.57 & 0.13 \\
$p_{4}$ & 0.41 & 0.13 & 0.36 & 0.19 & 0.53 & 0.24 & 0.07 & 0.29 & 0.46 & 0.53 & 0.28 & 0.40 \\
$p_{5}$ & 0.36 & 0.42 & 0.25 & 0.43 & 0.34 & 0.33 & 0.74 & 0.40 & 0.18 & 0.29 & 0.23 & 0.31 \\
$p_{6}$ & 0.26 & 0.53 & 0.16 & 0.11 & 0.37 & 0.63 & 0.20 & 0.54 & 0.26 & 0.35 & 0.33 & 0.13 \\
$p_{7}$ & 0.43 & 0.13 & 0.14 & 0.15 & 0.45 & 0.31 & 0.42 & 0.15 & 0.07 & 0.52 & 0.69 & 0.41 \\
$p_{8}$ & 0.25 & 0.38 & 0.42 & 0.27 & 0.49 & 0.46 & 0.07 & 0.51 & 0.62 & 0.16 & 0.40 & 0.20 \\
$p_{9}$ & 0.47 & 0.13 & 0.11 & 0.38 & 0.09 & 0.24 & 0.09 & 0.54 & 0.45 & 0.16 & 0.00 & 0.42 \\
$p_{10}$ & 0.40 & 0.15 & 0.38 & 0.53 & 0.26 & 0.38 & 0.47 & 0.18 & 0.15 & 0.86 & 0.24 & 0.40 \\
$p_{11}$ & 0.60 & 0.42 & 0.45 & 0.23 & 0.29 & 0.23 & 0.66 & 0.38 & 0.06 & 0.16 & 0.29 & 0.40 \\
$p_{12}$ & 0.20 & 0.18 & 0.15 & 0.44 & 0.28 & 0.16 & 0.30 & 0.21 & 0.34 & 0.48 & 0.36 & 0.21 \\
\hline
\end{tabular}

TABLE 9: Comprehensive performance of the three cases.

\begin{tabular}{lcccccc}
\hline Cases & & Candidate units & & \multicolumn{2}{c}{$\begin{array}{c}\text { Individual } \\
\text { performance }\end{array}$} & \multicolumn{2}{c}{$\begin{array}{c}\text { Collaborative } \\
\text { performance }\end{array}$} & $\begin{array}{c}\text { Comprehensive } \\
\text { performance }\end{array}$ \\
& Design units & Construction units & Suppliers & $Z_{1}$ & $Z_{2}$ & 2.34 \\
\hline Case 1 & 1 & 7 & 11 & 1.35 & 2.34 & 2.07 \\
Case 2 & 1 & 6 & 10 & 2.13 & 1.9 & 2.942 \\
Case 3 & 1 & 4 & 8 & 1.34 & & 1.9 \\
\hline
\end{tabular}




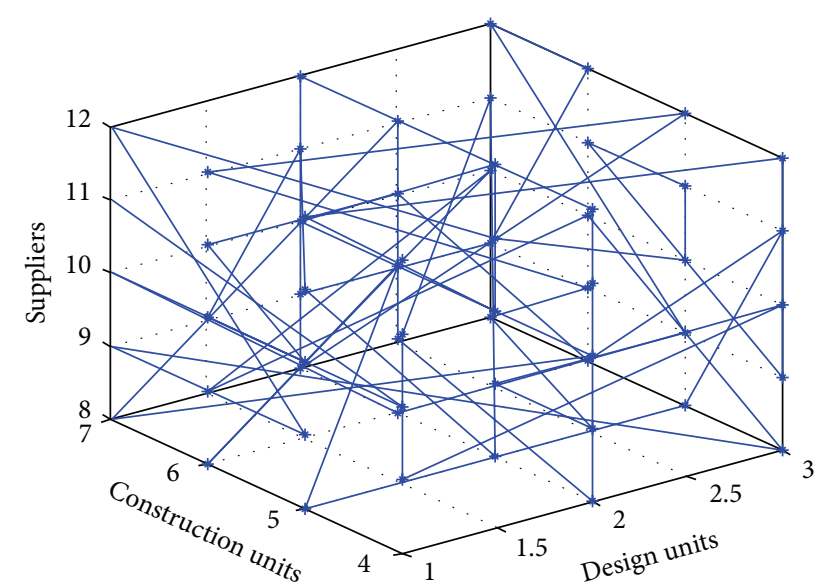

Figure 9: Case 3: selection schemes of design units, construction units, and suppliers in construction contractors under the circumstance of collaborative performance have greater weight than individual performance. Without loss of generality, we assumed $\lambda=$ $0.2, \mu=0.8$.

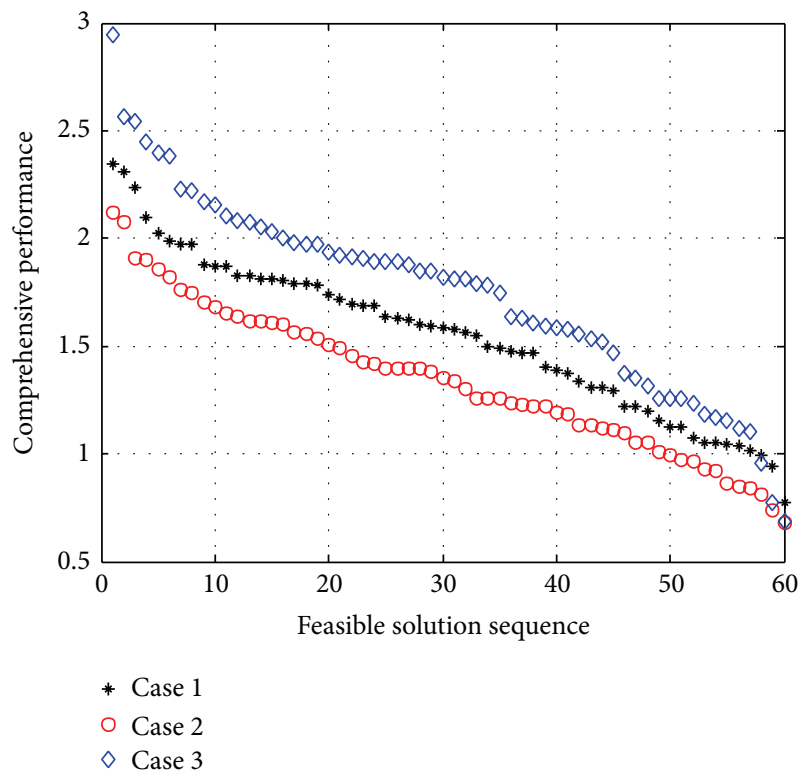

FIGURE 10: Comprehensive performance of selection schemes of design units, construction units, and suppliers in construction contractors according to the above three cases.

and constraints for the model. In addition, theory thoughts put forward in this paper are hoping to bring some enlightenment for bidding problems in construction projects.

\section{Notation}

$n$ : Total number of candidate units

$h$ : The total number of departments

$n_{j}$ : Number of candidate units in department $j, \sum_{j=1}^{h} n_{j}=n$

$q$ : Sum of departments

$q_{j}$ : Number of selected units in department $j$, $\sum_{j=1}^{h} q_{j}=q$ g: Number of individual indicators

$k$ : Number of collaborative indicators

$p_{i}:$ Candidate unit $i, i=1,2, \ldots, n$

$S_{j}$ : Set of candidate units in department $j$, $j=1, \ldots, h$

$N_{j}$ : Indicator set of candidate units in set $S_{j}$, $j=1, \ldots, h$

$I_{l}: \quad$ Individual indicator $l, l=1, \ldots, g$

$C_{m}$ : Collaborative indicator $m, m=1, \ldots, k$

$v_{l}$ : Weight of individual indicator $I_{l}, \sum_{l=1}^{g} v_{l}=1$; $0 \leq v_{l} \leq 1$

$w_{m}$ : Weight of collaborative indicator $C_{m}$, $\sum_{m=1}^{k} w_{m}=1 ; 0 \leq w_{m} \leq 1$

$x_{i}$ : Decision variables, $x_{i}=1$ denotes that unit $p_{i}$ is selected; or else, $x_{i}=0$.

\section{Competing Interests}

The authors declare that they have no competing interests regarding the publication of this paper.

\section{Acknowledgments}

This work was partly supported by the National Natural Science Foundation of Key Projects (no. 71390520), National Natural Science Foundation of China (nos. 71271103, 71101067, and 71571098), and Nanjing University Graduate Students Foundation of Scientific Innovation Projects (no. 2014CW05).

\section{References}

[1] R. Awwad, "Evolutionary simulation of contractors' learning and behavior under two bid-tendering approaches," Journal of Management in Engineering, vol. 32, no. 2, Article ID 04015041, 2016.

[2] S. Asgari, R. Awwad, A. Kandil, and I. Odeh, "Impact of considering need for work and risk on performance of construction contractors: an agent-based approach," Automation in Construction, vol. 65, pp. 9-20, 2016.

[3] J.-S. Chou, "Generalized linear model-based expert system for estimating the cost of transportation projects," Expert Systems with Applications, vol. 36, no. 3, pp. 4253-4267, 2009.

[4] M.-Y. Cheng, H.-C. Tsai, and E. Sudjono, "Conceptual cost estimates using evolutionary fuzzy hybrid neural network for projects in construction industry," Expert Systems with Applications, vol. 37, no. 6, pp. 4224-4231, 2010.

[5] D. K. H. Chua and D. Li, "Key factors in bid reasoning model," Journal of Construction Engineering and Management, vol. 126, no. 5, pp. 349-357, 2000.

[6] P. Ballesteros-Pérez, M. L. del Campo-Hitschfeld, D. MoraMelià, and D. Domínguez, "Modeling bidding competitiveness and position performance in multi-attribute construction auctions," Operations Research Perspectives, vol. 2, pp. 24-35, 2015.

[7] Z. Jin, F. Deng, H. Li, and M. Skitmore, "Practical framework for measuring performance of international construction firms," Journal of Construction Engineering and Management, vol. 139, no. 9, pp. 1154-1167, 2013.

[8] T.-H. Sohn, H.-R. Kim, and H.-S. Jang, "An MDB business competency assessment of Korean construction companies," 
KSCE Journal of Civil Engineering, vol. 18, no. 5, pp. 1314-1321, 2014.

[9] A. Mahdavi and M. Hastak, "Quantitative analysis of bidding strategies: a hybrid agent based-system dynamics approach," in Proceedings of the Construction Research Congress: Construction in a Global Network (CRC '14), pp. 1129-1138, May 2014.

[10] S. D. Jap and P. A. Naik, "BidAnalyzer: a method for estimation and selection of dynamic bidding models," Marketing Science, vol. 27, no. 6, pp. 949-960, 2008.

[11] I. Yu, K. Kim, Y. Jung, and S. Chin, "Comparable performance measurement system for construction companies," Journal of Management in Engineering, vol. 23, no. 3, pp. 131-139, 2007.

[12] C. M. Harper, K. R. Molenaar, S. Anderson, and C. Schexnayder, "Synthesis of performance measures for highway cost estimating," Journal of Management in Engineering, vol. 30, no. 3, Article ID 04014005, 2014.

[13] D. Schiereck and J. Vogt, "Long-run M \& A success of strategic bidders in the construction industry," Problems and Perspectives in Management, vol. 11, no. 4, pp. 46-67, 2013.

[14] M. Wanous, A. H. Boussabaine, and J. Lewis, "To bid or not to bid: a parametric solution," Construction Management and Economics, vol. 18, no. 4, pp. 457-466, 2000.

[15] A. Bagies and C. Fortune, "Bid/ no-bid decision modelling for construction projects," in Proceedings of the 22nd Annual Conference on Association of Researchers in Construction Management (ARCOM '06), pp. 511-521, Birmingham, UK, September 2006.

[16] M. S. El-Mashaleh, "Empirical framework for making the Bid/No-Bid decision," Journal of Management in Engineering, vol. 29, no. 3, pp. 200-205, 2013.

[17] M.-Y. Cheng, C.-C. Hsiang, H.-C. Tsai, and H.-L. Do, "Bidding decision making for construction company using a multicriteria prospect model," Journal of Civil Engineering and Management, vol. 17, no. 3, pp. 424-436, 2011.

[18] I. Dikmen, M. T. Birgonul, and A. K. Gur, "A case-based decision support tool for bid mark-up estimation of international construction projects," Automation in Construction, vol. 17, no. 1, pp. 30-44, 2007.

[19] J.-S. Chou, A.-D. Pham, and H. Wang, "Bidding strategy to support decision-making by integrating fuzzy AHP and regression-based simulation," Automation in Construction, vol. 35, pp. 517-527, 2013.

[20] D. J. Lowe and J. Parvar, "A logistic regression approach to modelling the contractor's decision to bid," Construction Management and Economics, vol. 22, no. 6, pp. 643-653, 2004.

[21] B. Liu, T. Huo, J. Meng, J. Gong, Q. Shen, and T. Sun, "Identification of key contractor characteristic factors that affect project success under different project delivery systems: empirical analysis based on a group of data from China," Journal of Management in Engineering, vol. 32, no. 1, Article ID 5015003, 2016.

[22] E. A. Demirtas and Ö. Üstün, "An integrated multiobjective decision making process for supplier selection and order allocation," Omega, vol. 36, no. 1, pp. 76-90, 2008.

[23] F. Khosrowshahi, "Neural network model for contractors' prequalification for local authority projects," Engineering, Construction and Architectural Management, vol. 6, no. 3, pp. 315328, 1999.

[24] I. M. Mahdi, M. J. Riley, S. M. Fereig, and A. P. Alex, "A multi-criteria approach to contractor selection," Engineering Construction and Architectural Management, vol. 9, no. 1, pp. 29-37, 2002.
[25] Y. I. Topcu, "A decision model proposal for construction contractor selection in Turkey," Building and Environment, vol. 39, no. 4, pp. 469-481, 2004.

[26] B. McCabe, V. Tran, and J. Ramani, "Construction prequalification using data envelopment analysis," Canadian Journal of Civil Engineering, vol. 32, no. 1, pp. 183-193, 2005.

[27] K. K. Lai, S. L. Liu, and S. Y. Wang, "A method used for evaluating bids in the Chinese construction industry," International Journal of Project Management, vol. 22, no. 3, pp. 193-201, 2004.

[28] E. W. L. Cheng and H. Li, "Contractor selection using the analytic network process," Construction Management and Economics, vol. 22, no. 10, pp. 1021-1032, 2004.

[29] H. Missbauer and W. Hauber, "Bid calculation for construction projects: regulations and incentive effects of unit price contracts," The European Journal of Operational Research, vol. 171, no. 3, pp. 1005-1019, 2006.

[30] S. Lambropoulos, "The use of time and cost utility for construction contract award under European Union Legislation," Building and Environment, vol. 42, no. 1, pp. 452-463, 2007.

[31] S. S. Padhi and P. K. J. Mohapatra, "Centralized bid evaluation for awarding of construction projects-a case of India government," International Journal of Project Management, vol. 28, no. 3, pp. 275-284, 2010.

[32] B. S. Liu, T. F. Huo, P. C. Liao, J. Gong, and B. Xue, "A group decision-making aggregation model for contractor selection in large scale construction projects based on two-stage partial least squares (PLS) path modeling," Group Decision \& Negotiation, vol. 24, no. 5, pp. 855-883, 2014.

[33] A. T. de Almeida, "Multicriteria decision model for outsourcing contracts selection based on utility function and ELECTRE method," Computers \& Operations Research, vol. 34, no. 12, pp. 3569-3574, 2007.

[34] L. H. Alencar and A. T. de Almeida, "Multicriteria decision group model for the selection of suppliers," Pesquisa Operacional, vol. 28, no. 2, pp. 321-337, 2008.

[35] A. J. de Melo Brito, A. de Almeida Filho, and A. T. de Almeida, "Multi-criteria decision model for selecting repair contracts by applying utility theory and variable interdependent parameters," IMA Journal of Management Mathematics, vol. 21, no. 4, pp. 349-361, 2010.

[36] F. Chiclana, E. Herrera-Viedma, F. Herrera, and S. Alonso, "Some induced ordered weighted averaging operators and their use for solving group decision-making problems based on fuzzy preference relations," The European Journal of Operational Research, vol. 182, no. 1, pp. 383-399, 2007.

[37] I. J. Pérez, F. J. Cabrerizo, S. Alonso, and E. Herrera-Viedma, "A new consensus model for group decision making problems with non-homogeneous experts," IEEE Transactions on Systems, Man, and Cybernetics: Systems, vol. 44, no. 4, pp. 494-498, 2014.

[38] A. Nosratinia and T. E. Hunter, "Grouping and partner selection in cooperative wireless networks," IEEE Journal on Selected Areas in Communications, vol. 25, no. 2, pp. 369-378, 2007.

[39] C. C. Kuo, F. Glover, and K. S. Dhir, "Analyzing and modeling the maximum diversity problem by Zero-one programming," Decision Sciences, vol. 24, no. 6, pp. 1171-1185, 1993.

[40] R. K. Gupta, K. S. Shishodia, and G. S. Sekhon, "Optimization of grinding process parameters using enumeration method," Journal of Materials Processing Technology, vol. 112, no. 1, pp. 6367, 2001.

[41] Q. Long, C. Wu, T. Huang, and X. Wang, "A genetic algorithm for unconstrained multi-objective optimization," Swarm and Evolutionary Computation, vol. 22, pp. 1-14, 2015. 
[42] Q. Long and C. Wu, "A hybrid method combining genetic algorithm and Hooke-Jeeves method for constrained global optimization," Journal of Industrial and Management Optimization, vol. 10, no. 4, pp. 1279-1296, 2014.

[43] H. Holland, Adaptation in Natural and Artificial Systems: An Introductory Analysis with Applications to Biology, Control, and Artificial Intelligence, University of Michigan Press, Ann Arbor, Mich, USA, 1992. 


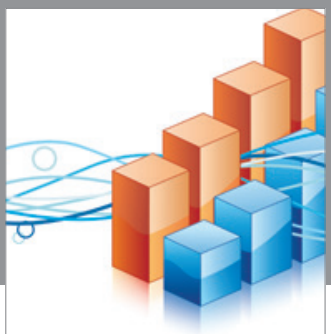

Advances in

Operations Research

vatem alat4

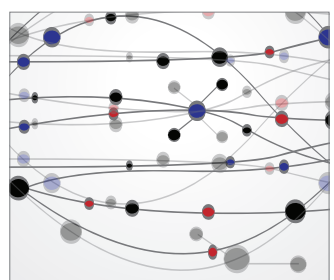

\section{The Scientific} World Journal
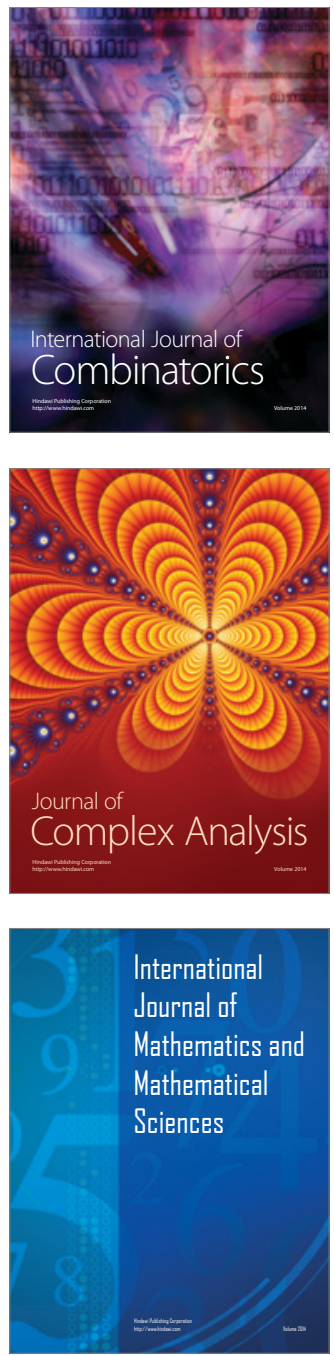
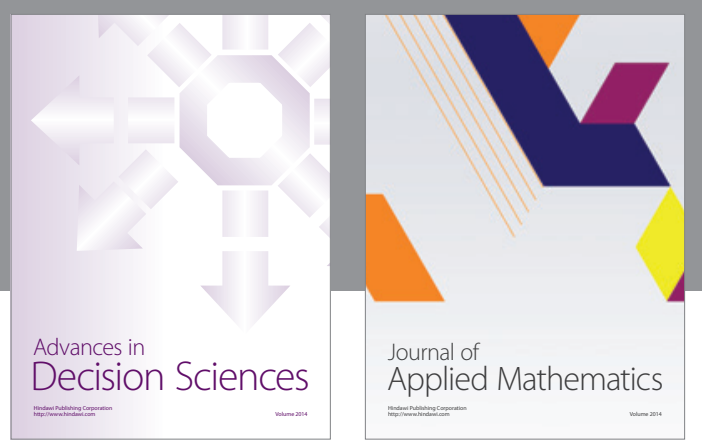

Algebra

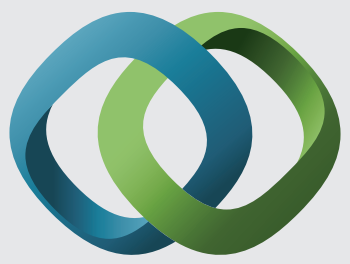

\section{Hindawi}

Submit your manuscripts at

http://www.hindawi.com
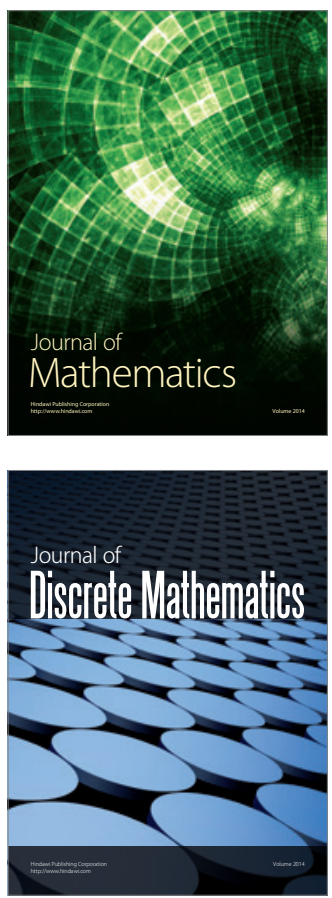

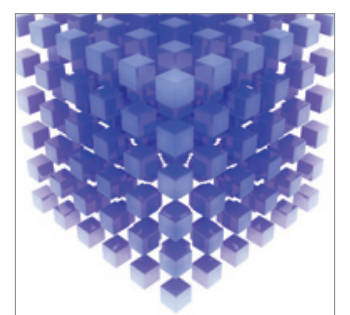

Mathematical Problems in Engineering
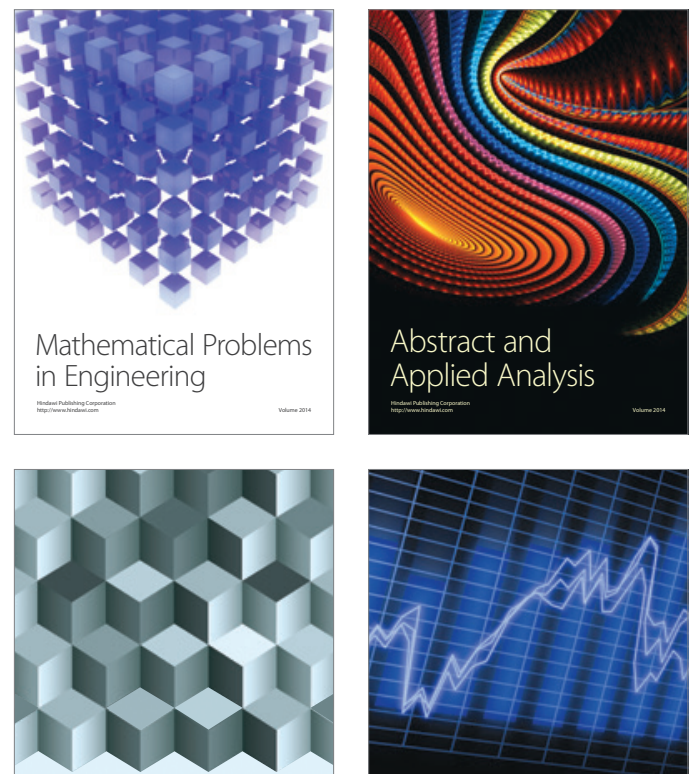

Journal of

Function Spaces

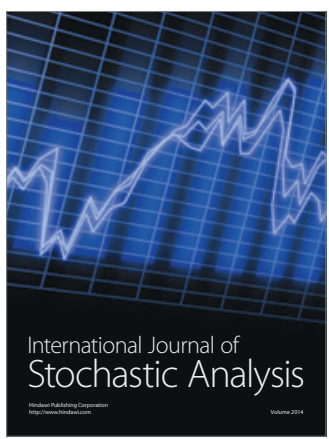

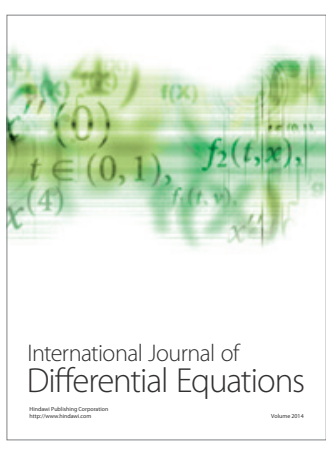
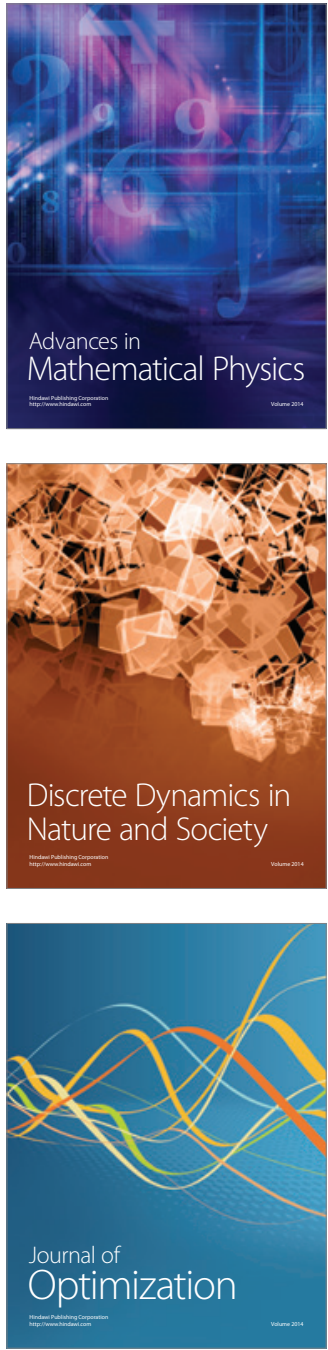